\title{
The Assessment of Thyroid Hormone Levels in Term and Preterm Infants Diagnosed with Transient Tachypnea of the Newborn: A Cross-Sectional Study
}

\author{
- Emel Ataoglu, ๑ Burcu Cebeci, ๑ Demet Oguz, • Dilek Kurnaz, ๑ Derya Buyukkayhan \\ University of Health Sciences Turkey, Haseki Training and Research Hospital, Clinic of Neonatology, Istanbul, Turkey
}

Abstract

\begin{abstract}
Aim: The study aims to evaluate the effect of thyroid hormone levels on the development of transient tachypnea of the newborn (TTN) and neonatal outcomes in preterm and term infants during hospitalization.

Methods: Eighty-seven newborns with gestational age $\geq 34$ weeks admitted to neonatal intensive care unit (NICU) between January 2016 and December 2019 were enrolled in our retrospective study. The hospital database system and patient files were scanned for data collection. Infants were divided into three groups (late preterm, early term, and term). Maternal features and demographic characteristics, thyroid hormones, neonatal outcomes during hospitalization of newborns with TTN were recorded.

Results: The mean fT4 level was $1.51 \pm 0.33 \mathrm{ng} / \mathrm{dL}$ and the median thyroid-stimulating hormone (TSH) level was $3.1 \mathrm{mIU} / \mathrm{L}$. Among 87 infants, 21 were late-preterm, 41 were early-term, and 25 were term infants. There was no difference in the mode of delivery, gender, need, and duration of mechanical ventilation, and non-invasive ventilation or $\mathrm{O}_{2}$ therapy. The mean fT4 level was $1.35 \pm 0.29 \mathrm{ng} / \mathrm{dL}$ in late preterms $2.5 \pm 2.1 \mathrm{ng} / \mathrm{dL}$ in early terms and $1.56 \pm 0.25 \mathrm{ng} / \mathrm{dL}$ in term infants. Late preterms had a lower fT4 level than early term and term groups which was statistically significant but no difference was present between subgroups in TSH levels.
\end{abstract}

Conclusion: Evaluation of thyroid function should be considered especially in preterm babies hospitalized to NICU because of respiratory distress for an individualized approach if treatment is needed.

Keywords: Newborn, thyroid hormones, transient tachypnea of newborn

\section{Introduction}

Transient tachypnea of the newborn (TTN) is described as a benign, respiratory condition mostly in late preterm and term newborns. Even though TTN is a self-limiting and spontaneously resolves within 48-72 hours in the majority, occasionally there is a need for hospitalization in the neonatal intensive care unit (NICU) and may cause morbidities like hypoxemia, pulmonary air leak syndrome, persistent pulmonary hypertension, and mortality (1-3).

The main underlying pathology is delayed reabsorption of lung alveolar fluid and failure of the lung to expand which is crucial for the transition from placental to pulmonary gas exchange (4). During the postnatal respiratory adaptation, alveolar epithelial cells take place in the transport of active solutes creating osmotic gradients results in alveolar fluid clearance (5). $\mathrm{Na}+\mathrm{K}+-A T P a s e$ and epithelial Na channels play a major role during this process (6). At birth, amiloride-sensitive sodium is transported via passive movement from the lumen to the alveolar epithelial cells through and sodium is extruded from the cell across the basolateral membrane to the interstitium

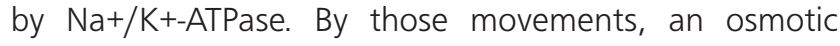
gradient is generated and pulmonary fluid passively passes through the intercellular space (7-9). Hormones like glucocorticoids, thyroid hormones, and catecholamines have a regulatory effect during the activity of sodium absorption which happens just before or in the course of delivery (6). Hypothyroidism has an inhibitory effect on fetal lung fluid resorption in utero (10). Preterm newborns have low levels of both total and free thyroxin which rise by gestational week and are found in higher levels than

Address for Correspondence: Emel Ataoglu, University of Health Sciences Turkey, Haseki Training and Research Hospital, Clinic of Neonatology, Istanbul, Turkey E-mail: emel984@gmail.com ORCID: orcid.org/0000-0001-7713-7185 Received: 22.02.2021 Accepted: 10.03.2021 
fetal concentrations after postnatal 4 to 5 days with the surge of thyroid-stimulating hormone (TSH) $(11,12)$.

Although risk factors for TTN are well established in the literature, there is limited knowledge about the effect of thyroid hormones on the development of TTN in preterm and term infants. Several studies are reporting the fT4 and TSH levels in preterm and term infants with TTN but there is limited information about neonatal outcome during hospitalization. So we aimed to evaluate thyroid functions related to neonatal outcomes among term and preterm newborns diagnosed with TTN who were admitted to our NICU (11,13-16).

\section{Methods}

\section{Study Design}

Newborns with gestational weeks (GW) above 33 weeks who were hospitalized to our NICU between January 2016 and December 2019 were enrolled in our retrospective study. A total number of 4450 newborns were born in our hospital during this study period and 618 babies were admitted to our NICU. Among these babies, 106 infants were diagnosed with TTN, 19 of them were excluded because of incomplete data for thyroid hormones and finally, 87 infants were included in the study. These 87 infants were divided into three subgroups and comparatively analyzed (late preterm-n; 21, early term-n; 41 and term-n; 25) (Figure 1) Hospital database

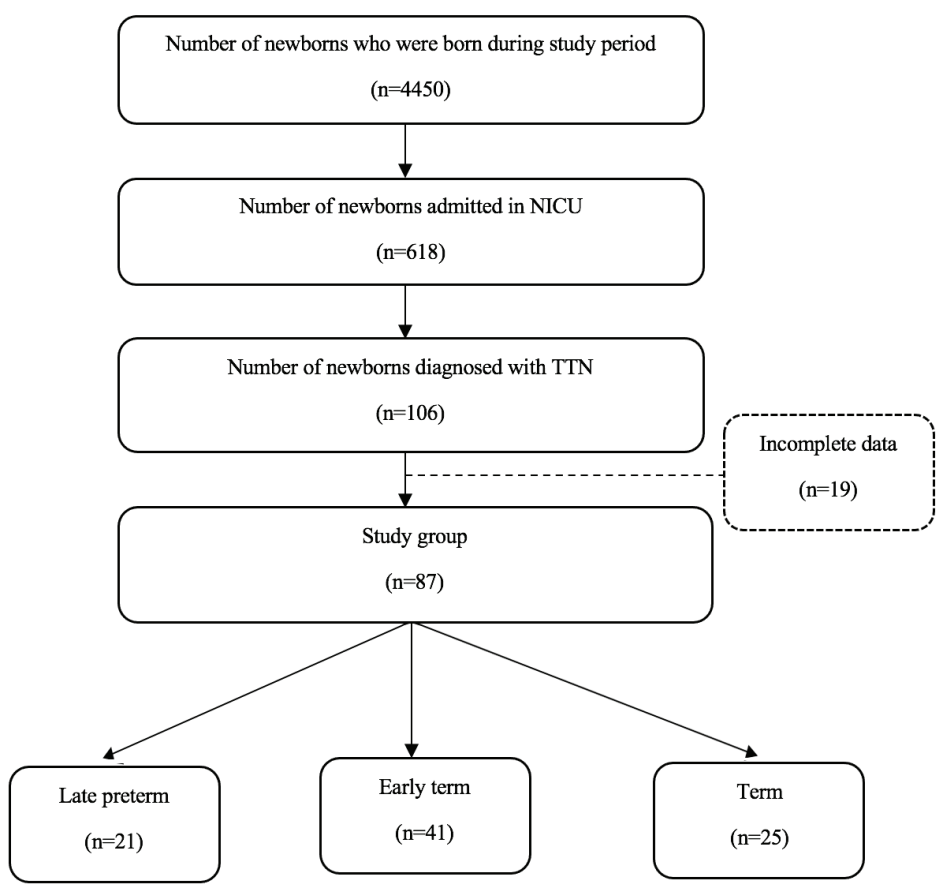

Figure 1. Flow diagram of the study NICU: Neonatal intensive care unit, TTN: Transient tachypnea of the newborn system and patient files were scanned for data collection and data on maternal features such as maternal age, parity, birth weight, gender, GW, the mode of delivery, Apgar scores ( $1^{\text {st }}$ and $5^{\text {th }}$ minute), need of oxygen or mechanical ventilation support, length of hospital stay, mortality and fT4 and TSH levels were recorded. Congenital metabolic disorders, pneumothorax, early-onset sepsis, hypoxic ischemic encephalopathy, major congenital anomalies, and congenital hypothyroidism or received thyroid hormone therapy were our major exclusion criteria.

All procedures performed in studies involving human participants were in accordance with the ethical standards of the institutional and/or national research committee and with the 1964 Helsinki Declaration and its later amendments or comparable ethical standards. This article does not contain any studies with animals performed by any of the authors. Ethical clearance was obtained from the Ethics Committee of Haseki Training and Research Hospital date and report number: 08.07.2020 - 2020-143.

\section{Neonatal Features}

Three subgroups were determined for newborns in accordance with the GW. Late-preterm newborns included babies who were born between 34 to $36+6$ weeks, early-term newborns included babies from 37 to $38+6$ weeks and term newborns from 39 to $41+6$ weeks. GW was determined according to the beginning of the mother's last menstrual period or first-trimester ultrasonography. TTN diagnosis was established according to both clinical and laboratory criteria: 1) presence of tachypnea (respiratory rate $>60$ breaths/min, retractions, nasal flaring, grunting, cyanosis) for minimum of 12 hours, 2) supplemental oxygen support for minimum of 6 hours, 3) radiological findings of TTN (increased central vascular structures, widened interlobar fissure, increased in both hemithorax and flattened diaphragmatic domes, 4) exclusion of pulmonary problems (respiratory distress syndrome, meconium aspiration, congenital pneumonia or heart disease, and other conditions leading to tachypnea such as hypoglycemia, hypocalcemia, polycythemia), in newborns who admitted to NICU (2).

Blood samples were routinely taken for fT4 and TSH levels via venipuncture within postnatal 72 hours in our unit for the newborn metabolic and endocrine disease screening program. Electrochemiluminescence immunoassay system was used to measure levels of fT4 and TSH. TSH reference range was 0.38-5.33 $\mathrm{mIU} / \mathrm{L}$ and fT4 reference range was 0.61-1.12 ng/dL.

\section{Statistical Analysis}

Results were analyzed with SPSS (Statistical Package for the Social Sciences, version 20 software) statistical program. The descriptive statistics are described with 
mean \pm standard deviation for normally distributed variables and median values ( $25^{\text {th }}-75^{\text {th }}$ percentile) for nonhomogeneously distributed variables, and as a frequency (percentage) for categorical variables. The conformity of variables to normal distribution was assessed using visual (histogram and probability graphs) and analytical methods (Kolmogorov-Smirnov/Shapiro-Wilk tests). For multiple group comparisons of categorical variables, the chi-square test was used when the chi-square condition was met and Fisher's exact test was used when the chi-square condition was not met. In multiple group comparisons of numerical variables, the analysis of variance (ANOVA) test was used for normally distributed numerical variables, and the Kruskal-Wallis test was used for non-normally distributed numerical variables. In the post-hoc analysis, the MannWhitney $U$ test with Bonferroni correction was used for sub-group analysis of non-normally distributed variables, and the chi-square test with Bonferroni correction was used for sub-group analysis of categorical variables. Statistical significance was considered as $p<0.05$.

\section{Results}

The mean GA of all infants was $37.5 \pm 1.5$ weeks and the mean birth weight was $3041 \pm 507 \mathrm{~g}$. The mean fT4 level was $1.51 \pm 0.33 \mathrm{ng} / \mathrm{dL}$ and the median TSH level was 3.1 [interquartile range (IQR) 1.8 to 4.7] $\mathrm{mIU} / \mathrm{L}$. Demographic characteristics, maternal features, and neonatal outcomes of all infants and comparison of three subgroups are given in the Table 1.

Among 87 infants, 21 (24.1\%) of them were latepreterm, $41(47.1 \%)$ of them were early-term, and 25 $(28.7 \%)$ of them were term infants. The mean gestational week and birth weight of late preterm, early term, and term newborns were respectively $35.4 \pm 0.6$ weeks, $37.5 \pm 0.5$ weeks, $39.4 \pm 0.7$ weeks and $2631 \pm 288 \mathrm{~g}, 3081 \pm 521 \mathrm{~g}$, $3320 \pm 410 \mathrm{~g}$. There were statistically significant differences in birth weight of the groups when subgroup analysis was performed according to the gestational week and the gestational week was significantly different between late preterm and early term group. Neither mode of delivery nor male gender was significantly different between the three subgroups. No significant difference was found for mechanical ventilation support and duration and noninvasive ventilation or $\mathrm{O}_{2}$ therapy. The mean fT4 level was $1.35 \pm 0.29 \mathrm{ng} / \mathrm{dL}$ in late preterm infants, $2.5 \pm 2.1 \mathrm{ng} / \mathrm{dL}$ in early term infants, and $1.56 \pm 0.25 \mathrm{ng} / \mathrm{dL}$ in term infants. Late preterm newborns had a low fT4 level compared to the other groups with a statistically significant difference. The median TSH level was $2.98 \mathrm{mIU} / \mathrm{L}$ (2.22 to 3.92) in preterm group, $3.29 \mathrm{mIU} / \mathrm{L}$ (1.88 to 5.85 ) in the term term infants and $3.24 \mathrm{mIU} / \mathrm{L}$ (1.57 to 4.87 ) in term group. No significant difference was found for TSH levels in subgroups. TSH and fT4 levels of all groups and subgroups were given in the Table 2.

The median hospitalization duration was 9 days (IQR) 7 to 14.5 for preterm infants, 8 days (IQR 6 to 10) for early term infants, and 8 days (IQR 5 to 10). No significant difference was found for hospitalization duration among the groups. No patient died in both three groups.

\section{Discussion}

We evaluated the thyroid hormone levels in total number of 87 late preterm and term diagnosed with TTN. Our study demonstrated that fT4 levels were significantly lower in late preterms compared with early-term and term newborns. During postnatal adaptation, fT4 and total T4 levels have low levels and as TSH has a rise within 4-5 days after birth, concentrations of T4 begin to increase which is directly proportional to gestational age of the newborn (12). Late preterm babies have physiological immaturation so they tend to have more respiratory adaptation problems that sometimes result in TTN as a consequence of delayed transition from fetal life during the postnatal period $(13,17)$. Late preterm infants do not have mature hypothalamic-pituitary-thyroid axis which is assumed as a robust factor to adapt to life after birth (18). This information supports our major finding in the study that lower fT4 values were detected in late-preterm babies, similar levels between early term and term newborns. In the literature, some studies reported similar results as in our study. Kayıran et al. (14) evaluated thyroid hormone levels in newborns with TTN, categorized by GW and compared with healthy newborns. They reported that fT4 levels of the newborns with TTN were significantly lower in late-preterms than healthy babies and early-term and term neonates with TTN had higher TSH levels (14). Atasay et al. (15) also studied cord blood TSH, free T3 (fT3), fT4, cortisol, epinephrine, and adrenocorticotropic hormone in the newborns having TTN and compared to the healthy group. There was no significant difference for both fT4 and TSH levels was significantly different but newborns having TTN had significantly lower fT3 levels. No significant difference was found between groups for TSH levels in our study and fT3 levels could not be evaluated since the study was designed as retrospective.

Several previous studies reported the relation between thyroid hormones and respiratory diseases. The study of Paul et al. (19) showed that there was an important relationship between low fT4 and severity of disease after birth. Low fT4 levels were found to be related to increased respiratory disease in late preterm babies (19). We found no significant difference in respiratory morbidities among late preterm and term infants. Lim et al. (20) evaluated thyroid function including total T4 and 
TSH but not the bioavailable form as fT4 in term infants who were mechanically ventilated in their retrospective study. Biswas et al. (16) reported lower levels of fT4 in mechanically ventilated preterm infants who were born $<30 \mathrm{GW}$. Vanhole et al. (21) also found that low thyroid hormone levels were related with worse neonatal outcomes. Although late preterm infants have lower fT4 levels than term infants, we did not find any difference in need and duration of invasive or non-invasive mechanical ventilation, hospital stay, and death among late preterm and term newborns.
In several studies as cesarian section is found as one of the leading risk factors for the development of TTN (22-24). There was no significant difference in the mode of delivery between groups in our study and cesarian section was not found related to the development of TTN similar to the studies of Kayıran et al. (14) and Zanardo et al. (25). Same findings were available for the relation between male gender and TTN among groups. There was no difference in gender for late preterm and term infants.

\begin{tabular}{|c|c|c|c|c|c|c|}
\hline Characteristic & & $\begin{array}{l}\text { All patients } \\
(\mathrm{n}=87)\end{array}$ & $\begin{array}{l}\text { Late preterm } \\
(\mathrm{n}=21)\end{array}$ & $\begin{array}{l}\text { Early term } \\
(n=41)\end{array}$ & $\begin{array}{l}\text { Term } \\
(\mathrm{n}=25)\end{array}$ & p \\
\hline \multicolumn{7}{|c|}{ Demographic information } \\
\hline \multicolumn{2}{|c|}{ Maternal age (years), mean \pm SD } & $28.0 \pm 6.9$ & $26.8 \pm 6.3$ & $28.5 \pm 7.3$ & $28.2 \pm 6.6$ & 0.750 \\
\hline \multicolumn{2}{|c|}{ Gravida, median (IQR 25-75) } & $2(1$ to 3$)$ & $2(2-3)$ & $2(1$ to 3$)$ & $2(1$ to 3$)$ & 0.619 \\
\hline $\begin{array}{l}\text { Mode of delivery, } \\
\mathrm{n} / \mathrm{N}(\%)\end{array}$ & $\mathrm{C} / \mathrm{S}$ & $54 / 87(62.1)$ & $11 / 21(52.4)$ & 29/41 (70.7) & $14 / 25(56)$ & 0.286 \\
\hline Gender, n/N (\%) & Male & $54 / 87(62.1)$ & $13 / 21(61.9)$ & $25 / 41(61)$ & $16 / 25(64)$ & 0.970 \\
\hline $\begin{array}{l}\text { Gestational age } \\
\text { (week), mean } \pm \text { SD }\end{array}$ & - & $37.5 \pm 1.5$ & $35.4 \pm 0.6$ & $37.5 \pm 0.5$ & $39.4 \pm 0.7$ & $<0.001^{a, b}$ \\
\hline $\begin{array}{l}\text { Birth weight }(\mathrm{g}) \text {, } \\
\text { mean } \pm \mathrm{SD}\end{array}$ & - & $3041 \pm 507$ & $2631 \pm 288$ & $3081 \pm 521$ & $3320 \pm 410$ & $<0.001^{a, b, c}$ \\
\hline \multirow{4}{*}{ Cord blood gases } & pH, median (IQR 25-75) & $\begin{array}{l}7.31 \text { (7.28 to } \\
7.35)\end{array}$ & $\begin{array}{l}7.3(7.28 \text { to } \\
7.34)\end{array}$ & 7.31 (7.28 to 7.35$)$ & $7.31(7.25-7.34)$ & 0.756 \\
\hline & $\begin{array}{l}\text { Base excess, median (IQR } \\
\text { 25-75) }\end{array}$ & $-3.1(-6.3$ to -1.5$)$ & $-3.1(-5.1$ to -1.0$)$ & $-3.0(-6.4$ to -1.7$)$ & $-3.40(-7.0$ to -1.6$)$ & 0.848 \\
\hline & Bicarbonate, mean \pm SD & $20.2 \pm 3.3$ & $20.4 \pm 0.7$ & $20.1 \pm 2.9$ & $20.1 \pm 3.8$ & 0.562 \\
\hline & Lactate, mean \pm SD & $2.1 \pm 1.6$ & $1.5 \pm 1.3$ & $2.07 \pm 1.4$ & $2.6 \pm 1.9$ & 0.162 \\
\hline \multirow{2}{*}{ APGAR scores } & 15t-minute, median (IQR 25-75) & $8(7$ to 9$)$ & $8(7$ to 9$)$ & $8(7$ to 9$)$ & $8(6$ to 9$)$ & 0.509 \\
\hline & $5^{\text {th }}$-minute, median (IQR 25-75) & $9(9$ to 10$)$ & $9(9$ to 10$)$ & $9(9$ to 10$)$ & $9(8.5$ to 10$)$ & 0.773 \\
\hline \multirow{5}{*}{ Respiratory status } & Need of MV, n/N (\%) & $8 / 87(9.2)$ & $3 / 21(14.3)$ & $2 / 41(4.9)$ & $3 / 25(12)$ & 0.410 \\
\hline & Duration of $\mathrm{MV}$, mean $\pm \mathrm{SD}$ & $2.3 \pm 2.1$ & $1.33 \pm 0.57$ & $2.5 \pm 2.1$ & $3.3 \pm 3.2$ & 0.607 \\
\hline & Need of NIMV, n/N (\%) & $40 / 87(46)$ & $14 / 21(66.7)$ & 15/41 (36.6) & $11 / 25(44)$ & 0.08 \\
\hline & $\begin{array}{l}\text { Duration of NIMV, median (IQR } \\
\text { 25-75) }\end{array}$ & $2(1$ to 2$)$ & $1.5(1-3)$ & $2(1$ to 2$)$ & $1(1$ to 2$)$ & 0.750 \\
\hline & $\begin{array}{l}\text { Duration of oxygen therapy, } \\
\text { median (IQR 25-75) }\end{array}$ & $2(1$ to 3$)$ & $2(1-3)$ & $2(1-3)$ & $1(1-2)$ & 0.448 \\
\hline \multirow[t]{2}{*}{ Outcome, n/N (\%) } & $\begin{array}{l}\text { Length of stay at hospital } \\
\text { (days), median (IQR 25-75) }\end{array}$ & 8 (6 to 10$)$ & $9(7$ to 14.5$)$ & $8(6$ to 10$)$ & $8(5$ to 10$)$ & 0.137 \\
\hline & Dead, n/N (\%) & $0 / 87(0)$ & $0 / 21(0)$ & $0 / 41(0)$ & $0 / 25(0)$ & 1 \\
\hline
\end{tabular}

\section{Table 2. Thyroid hormone levels of the newborns}

\section{Hormone levels}

fT4 $(\mathrm{ng} / \mathrm{dL})$, mean $\pm \mathrm{SD}$

TSH, (mIU/L), median (IQR 25-75)

\begin{tabular}{|l|l|}
\hline $\begin{array}{l}\text { All patients } \\
(\mathbf{n}=\mathbf{8 7})\end{array}$ & $\begin{array}{l}\text { Late preterm } \\
(\mathbf{n}=\mathbf{2 1})\end{array}$ \\
\hline $1.51 \pm 0.33$ & $1.35 \pm 0.29$ \\
\hline $3.1(1.8$ to 4.7$)$ & $2.98(2.22$ to 3.92$)$ \\
\hline
\end{tabular}

Early term
$(\mathrm{n}=41)$

$2.5 \pm 2.1$

$3.29(1.88-5.85)$
Term

$(\mathbf{n}=25)$

$\mathbf{p}$

$1.56 \pm 0.25$

$3.24(1.57$ to 4.87$) \quad 0.678$

${ }^{a}$ Different from Late Preterm + Early Term, ${ }^{b}$ Different from Late Preterm + Term group

fT4: Free Thyroxin 4, TSH: Thyroid stimulating hormone, SD: Standart deviation, IQR: Interquartile range 


\section{Study Limitations}

This study has some limitations. Our study was a singlecenter study representing a small number of infants. We could not compare with healthy infants since it was designed as retrospective. Further prospective studies with a larger number of infants are needed to make a clear interpretation of the effect of thyroid hormones on respiratory diseases, especially in infants.

\section{Conclusion}

Preterm newborns had different thyroid hormones basically due to gestational age compared to term newborns diagnosed with TTN in our study. Evaluation of thyroid function should be considered especially in preterm newborns who were hospitalized to the NICU because of respiratory problems for an individualized approach if treatment is needed.

\section{Acknowledgments}

We would like to express our gratitude to the patients and their parents whose records were used in this study, without whom this research would not be possible.

\section{Authorship Contributions}

Concept: E.A., B.C., Design: E.A., B.C., Data Collection or Processing: E.A., B.C., Analysis or Interpretation: B.C., D.O., D.K., D.B., Literature Search: E.A., D.O., D.K., D.B., Writing: B.C.

Conflict of Interest: No conflict of interest was declared by the authors.

Financial Disclosure: The authors declared that this study received no financial support.

\section{References}

1. Bak SY, Shin YH, Jeon JH, et al. Prognostic factors for treatment outcomes in transient tachypnea of the newborn. Pediatr Int 2012;54:875-80.

2. Kasap B, Duman N, Ozer E, Tatli M, Kumral A, Ozkan H. Transient tachypnea of the newborn: predictive factor for prolonged tachypnea. Pediatr Int 2008;50:81-4.

3. Jain $\mathrm{L}$, Dudell GG. Respiratory transition in infants delivered by cesarean section. Semin Perinatol 2006;30:296-304.

4. Hjalmarson O. Epidemiology and classification of acute, neonatal respiratory disorders: a prospective study. Acta Paediatr Scand 1981;70:773-83.

5. Jain L. Alveolar fluid clearance in developing lungs and its role in neonatal transition. Clin Perinatol 1999;26:585-99.

6. Kaltofen T, Haase M, Thome UH, Laube M. Male sex is associated with a reducedalveolar epithelial sodium transport. PLoS One 2015;10:0136178.

7. Baines DL, Folkesson HG, Norlin A, Bingle CD, Yuan HT, Olver RE. The influence of mode of delivery, hormonal status and postnatal $\mathrm{O} 2$ environment on epithelial sodium channel ( $\mathrm{ENaC})$ expression in perinatal guineapig lung. J Physiol 2000;522:147-57.

8. Bland RD, Nielson DW. Developmental changes in lung epithelial ion transport and liquid movement. Annu Rev Physiol
1992;54:373-94

9. Barker PM, Olver RE. Clearance of lung liquid during the perinatal period. J Appl Physiol (1985) 2002;93:1542-8.

10. Kessel I, Makhoul IR, Sujov P. Congenital hypothyroidism and nonimmune hydrops fetalis: associated? Pediatrics 1999;103:E9.

11. Hume R, Simpson J, Delahunty $C$, et al. Human fetal and cord serum thyroid hormones: developmental trends and interrelationships. J Clin Endocrinol Metab 2004;89:4097-103.

12. Geraghty LE, O'Grady M. Neonatal Thyroid Function: Test First, Think Second? Ir Med J 2016;109:460.

13. Behme RM, Mackley AB, Bartoshesky L, Paul DA. Thyroid function in late preterm infants in relation to mode of delivery and respiratory support. J Pediatr Endocrinol Metab 2014;27:425-30.

14. Kayıran SM, Erçin S, Kayıran P, Gursoy T, Gurakan B. Relationship between thyroid hormone levels and transient tachypnea of the newborn in late-preterm, early-term, and term infants. J Matern Fetal Neonatal Med 2019;32:1342-6.

15. Atasay B, Ergun H, Okulu E, Mungan Akın I, Arsan S. The association between cord hormones and transient tachypnea of newborn in late preterm and term neonates who were delivered by cesarean section. J Matern Fetal Neonatal Med 2013;26:87780.

16. Biswas S, Buffery J, Enoch H, Bland JM, Walters D, Markiewicz M. A longitudinal assessment of thyroid hormone concentrations in preterm infants younger than 30 weeks' gestation during the first 2 weeks of life and their relationship to outcome. Pediatrics 2002;109:222-7.

17. Engle WA, Tomashek KM, Wallman C, Committee on Fetus and Newborn."Late-preterm" infants: a population at risk. American Academy of Pediatrics 2007;120:1390-401.

18. Fisher DA, Nelson JC, Carlton El, Wilcox RB. Maturation of human hypothalamic-pituitary-thyroid function and control. Thyroid 2000;10:229-34.

19. Paul DA, Mackley A, Yencha EM. Thyroid function in term and late preterm infants with respiratory distress in relation to severity of illness. Thyroid 2010;20:189-94.

20. Lim DJ, Herring MK, Leef KH, Getchell J, Bartoshesky LE, Paul DA. Hypothyroxinemia in mechanically ventilated term infants is associated with increased use of rescue therapies. Pediatrics 2005; 115:406-10.

21. Vanhole C, Aerssens P, Naulaers G, et al. L-thyroxine treatment of preterm newborns: clinical and endocrine effects. Pediatr Res 1997;42:87-92.

22. Shapiro-Mendoza CK,TomashekKM, KotelchuckM, et al. Effect of late-preterm birth and maternal medical conditions on newborn morbidity risk. Pediatrics 2008;121:223-32.

23. De LucaR, Boulvain M, Irion O, Berner M, Pfister RE. Incidence of early neonatal mortality and morbidity after late-preterm and term cesarean delivery. Pediatrics 2009;123:1064-71.

24. Derbent A, Tatli MM, Duran M, ve ark. Transient tachypnea of the newborn: effects of labor and delivery type in term and preterm pregnancies. Arch Gynecol Obstet 2011;283:947-51.

25. Zanardo V, Simbi AK, Franzoi M, Soldà G, Salvadori A, Trevisanuto D. Neonatal respiratory morbidity risk and mode of delivery at term: influence of timing of elective caesarean delivery. Acta Paediatr 2004;93:643-7. 